\title{
PROFISSÃO DOCENTE E SAÚDE DE PROFESSORES DA REDE MUNICIPAL DE ENSINO DA CIDADE DE MANAUS
}

\author{
PROFESIÓN DOCENTE Y SALUD DE PROFESORES DE LA RED MUNICIPAL DE \\ ENSEÑANZA DE LA CIUDAD DE MANAOS
}

\section{TEACHING PROFESSION AND HEALTH OF TEACHERS FROM THE MUNICIPAL NETWORK OF TEACHING IN THE CITY OF MANAUS}

\author{
Julia Graziela Bernardino de ARAÚJO QUEIROZ ${ }^{1}$ \\ Tatiana Andreza da SILVA MARINHO ${ }^{2}$
}

RESUMO: A profissão docente tem sido objeto de discussão nos últimos anos devido ao crescente número de professores que estão adoecendo, a cada dia, em pleno exercício da profissão. Neste sentido, a pesquisa pautou-se em analisar e descrever os fatores que estão relacionados ao desencadeamento de doenças de professores da educação básica na cidade de Manaus. A pesquisa é de abordagem qualitativa e foi conduzida em 32 escolas com 320 professores. Quanto aos fatores de estresse, de forma geral, a maior causa apontada pelos profissionais foram o baixo salário (62.4\%), a ausência de acompanhamento familiar na vida escolar dos discentes $(19.6 \%)$ e a infraestrutura precária do recinto escolar $(10.9 \%)$. As doenças psicossomáticas $(24 \%)$ foram as que mais afetaram os professores em pleno exercício da profissão. Com isso, há necessidade do desenvolvimento de políticas púbicas que visem a valorização dos profissionais da educação e a melhoria das condições de trabalho.

PALAVRAS-CHAVE: Saúde. Professor. Formação.

RESUMEN: La profesión docente ha sido objeto de discusión en los últimos años debido al creciente número de profesores que están enfermándose, a cada día, en pleno ejercicio de la profesión. En este sentido, la investigación se basó en analizar y describir los factores que están relacionados al desencadenamiento de enfermedades de profesores de la enseñanza básica en la ciudad de Manaos. La investigación tiene abordaje cualitativo y fue conducida en 32 colegios con 320 profesores. Cuanto a los factores de estrés, de manera general, la mayor causa señalada por los profesionales fueron el salario bajo (62.4\%), la ausencia de asistencia familiar en la vida escolar de los discentes (19.6\%) y la infraestructura precaria de las áreas escolares (10.9\%). Las enfermedades psicosomáticas (24\%) fueron las que más afectaron a los profesores en pleno ejercicio de la profesión. Con eso, hay la necesidad del desarrollo de políticas públicas destinadas a la valoración de profesionales de la educación y la mejoría de las condiciones de trabajo.

\footnotetext{
${ }^{1}$ Universidade Nilton Lins (UNINILTONLINS), Manaus - AM - Brasil. Coordenadora e Professora do Curso de Pedagogia. Doutoranda no Programa de Pós-graduação em Educação (UFSM). ORCID: https://orcid.org/0000-0002-7812-3014. E-mail: jgaraujo@niltonlins.br

${ }^{2}$ Secretaria Municipal de Educação (SEMED), Manaus - AM - Brasil. Professora de Ciências vinculada à Secretaria Municipal de Educação de Manaus. Doutorado em Biologia (Ecologia) (INPA). ORCID: https://orcid.org/0000-0001-8420-3371. E-mail: tasmarinho@gmail.com
} 
PALABRAS CLAVE: Salud. Profesor. Formación.

ABSTRACT: The teaching profession has been the subject of discussion in recent years due to the growing number of teachers who are getting sick every day, due to exercise of the profession. In this sense, the research was based on analyzing and describing the factors that are related to the triggering of illnesses of basic education teachers in the city of Manaus. The research has a qualitative approach and was conducted in 32 schools with 320 teachers. Regarding stress factors, in general, the main cause pointed out by the professionals was the low salary (62.4\%), the lack of family support in the students' school life (19.6\%) and the precarious infrastructure of the school grounds (10.9\%). Psychosomatic illnesses (24\%) were the ones that most affected teachers in the full exercise of their profession. Thus, there is a need to develop public policies aimed at valuing education professionals and improving working conditions.

KEYWORDS: Health. Teacher. Education.

\section{Introdução}

A profissão docente ao longo dos anos tem ocupado destaque em inúmeras pesquisas envolvendo processo formativo e práticas pedagógicas, no entanto, os desafios da atualidade frente às práticas educativas desenvolvidas pelos educadores dentro do ambiente escolar tem dado espaço a pesquisas relacionadas a saúde do professor e aos fatores a ela relacionados, em vista de um quadro de adoecimento dos profissionais da educação.

Assim, diante das transformações sociais e tecnológicas ocorridas na sociedade, surge a necessidade de pesquisas sobre a saúde do professor e as condições de trabalho docente (FREITAS; CRUZ, 2008). O docente nesse contexto de mudanças passou a assumir diversas funções e com isso, a entrada nas escolas de milhões de novos alunos e a presença de milhares de novos professores passou a exigir mudanças de práticas nas escolas e constitui grande desafio para o trabalho dos professores (FERREIRA, 2010, p. 21).

As primeiras notícias sobre o adoecimento do professor, causadas por alterações nas condições de trabalho, foram encontradas em países europeus como Suécia, França, Alemanha e Reino Unido no início da década de 80. Segundo Cruz (2010), o estresse e a síndrome de burnout eram apontados como os principais problemas entre professores naquela época, com implicações sobre o absenteísmo por doença e abandono da profissão.

Em 1987, os relatos do livro “O Mal Estar Docente” de José Manoel Esteve, eram considerados como principais na área e discutiam a respeito das tensões negativas associadas a ação do professor em sala de aula e as condições ambientais em que exerce a docência (PEREIRA, 2016). De acordo com o autor, as tensões negativas relacionadas aos problemas 
de saúde do professor abrangem mal-estar docente, angústia laboral, estresse profissional, esgotamento emocional, depressão, frustração e síndrome de burnout, que são também evidenciadas em outras pesquisas (ESTEVES, 1999; CODO; VASQUES-MENEZES, 1999; CARLOTTO, 2002; CARLOTTO; PALAZZO, 2006).

Portanto, a compreensão dos fatores responsáveis pelo aparecimento de doenças ocupacionais e distúrbios psíquicos em professores, tais como síndrome de burnout, distúrbios osteomusculares relacionados ao trabalho (DOR) e lesão por esforço repetitivo (LER), distúrbio na voz, depressão em diversos níveis e crises de ansiedade e de pânico, possibilita a discussão sobre o adoecimento do professor e os fatores que podem colaborar para o agravamento de tal quadro.

Diante do exposto, esta pesquisa tem por objetivo analisar e descrever os fatores que estão relacionados ao desencadeamento de doenças no exercício da profissão docente de professores da educação básica, ensino fundamental, da rede municipal de ensino de Manaus.

\section{Trajetória da Pesquisa}

A pesquisa é de abordagem qualitativa, também pode ser considerada do tipo exploratório-descritiva, pois a pesquisa exploratória corrobora com a pesquisa descritiva e prepara o caminho para o desenvolvimento da pesquisa, busca sua compreensão, familiarização com o fenômeno desconhecido e possibilita realizar uma pesquisa completa. Assim, os dados obtidos serão transformados em informação (HERNANDEZ SAMPIERE; COLADO; LUCIO, 2013).

O estudo foi conduzido em 32 escolas distribuídas em sete zonas distritais da rede municipal de ensino da cidade de Manaus. Foram aplicados questionários a professores considerando os seguintes critérios de inclusão: professores em regime de 40h, faixa etária de 25 a 60 anos, ambos os sexos, professores que atuassem do $1^{\circ}$ ao $5^{\circ}$ ano, professores que aceitassem participar da pesquisa e que assinassem o TCLE (Termo de Consentimento Livre e Esclarecido). Os critérios de exclusão compreenderam professores demitidos ou exonerados durante a pesquisa, professores readaptados, faixa etária inferior a 25 anos e professores de educação infantil.

A Secretaria Municipal de Educação (SEMED) não utiliza a distribuição por zona segundo a divisão do município de Manaus, que contém seis zonas. Sendo assim, as zonas distritais da SEMED são: Sul que abrange a Centro-Sul, Leste I, Leste II, Oeste, CentroOeste, Norte e Rural que também é composta pelas zonas Rodoviária e Ribeirinha. 
Em cada uma das escolas foram selecionados 10 professores, perfazendo um total de 320 professores que seriam entrevistados do universo de 1.772 professores de 40 horas da SEMED de Manaus. A quantidade de professores entrevistados seguiu o cálculo amostral que compreendeu: tamanho da população, nível de confiança de $95 \%$ e margem de erro de 5\%.

Pelo fato de a pesquisa envolver diretamente seres humanos, o estudo foi submetido ao Comitê de ética em Pesquisa por meio da Plataforma Brasil, onde foi acompanhando e creditado em observação a resolução do Conselho Nacional de Saúde - CNS 466/2012 sendo aprovado pelo Número do Parecer: 1.982.536. Assim, a pesquisa seguiu todas as diretrizes atendendo aos fundamentos éticos e científicos exigidos na Resolução de nº 466/2012 do CNS.

Após a autorização do Comitê de Ética, foi realizada a pesquisa de campo nas escolas selecionadas, no primeiro momento foi realizada reunião com a gestão e professores da escola para exposição do projeto explicitando a respeito do objetivo e contribuição do trabalho.

No segundo momento, após a assinatura do TCLE, os questionários foram entregues para serem respondidos pelos professores e devolvidos as pesquisadoras. Os questionários continham 10 perguntas, sendo nove perguntas de múltipla escolha e uma pergunta aberta. Os eixos das questões envolviam perfil, formação, caracterização do ambiente escolar e fatores que levam ao desencadeamento de doenças.

\section{Resultados e discussão}

Nesta seção discorremos sobre os achados da pesquisa envolvendo aspectos pertinentes para análise e buscou-se articular com as principais produções científicas os resultados da mesma.

\section{Perfil dos professores}

Foi constatado que no exercício da docência, o gênero feminino predomina em todas as zonas distritais da rede de ensino de Manaus. Dessa forma, a mulher tem ocupado espaço no campo educacional e formação para atuar profissionalmente (Figura 1). 
Figura 1 - Gênero dos professores da Rede de ensino de Manaus nas Zonas Distritais da SEMED

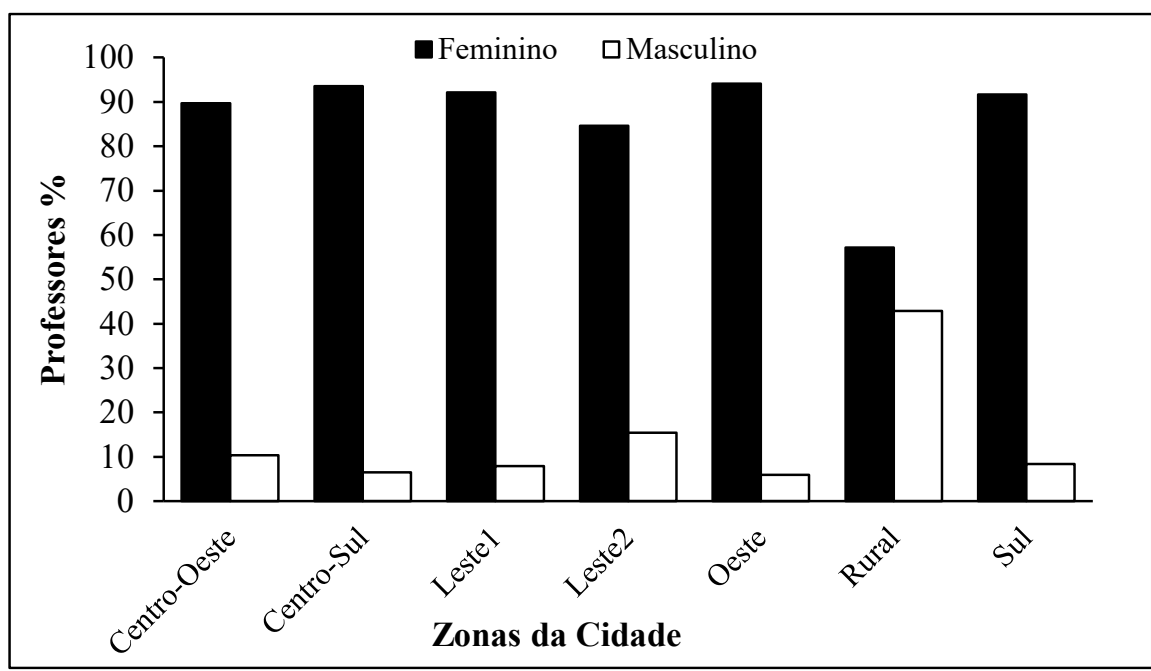

Fonte: Elaborado pelas autoras

Segundo Rabelo e Martins (2006), o contexto histórico da entrada da mulher no magistério ocorreu com a expansão do capitalismo, pois houve a necessidade de se investir na educação feminina. Assim, o magistério passou a ser constituído também por mulheres. No entanto, havia funções distintas para homens e mulheres atuarem na docência, em que as mulheres ensinavam as meninas e as instruíam para os afazeres domésticos e o necessário para viver em sociedade, enquanto os homens ensinavam os meninos diferentemente e tinham currículos distintos.

Com relação à faixa etária dos professores entrevistados nas zonas distritais, compreende o maior número de professores na faixa de 36 a 55 anos. Assim, a idade do grupo de professores investigados foi similar a de outros estudos como de Pereira, Teixeira e Lopes (2013) realizada com professores da educação básica, bem como o de Penteado (2007) no município de Rio Claro, sobre a voz do professor, assim como o de Costa e Rocha (2013), que investigaram a respeito dos fatores de estresse no contexto do trabalho docente. Essa faixa etária também pode sinalizar segundo Machado (2015) maior experiência em práticas pedagógicas e atuação em sala de aula.

\section{Formação dos professores}

Considerando o nível de formação do total de professores participantes, $43.7 \%$ possui graduação e a zona com maior número de graduados foi a zona Leste 1 com 55. 3\% (Figura 
2). Quanto ao número de professores com especialização latu sensu os resultados mostraram um percentual de $51.5 \%$ dos entrevistados, sendo que na zona sul $66.7 \%$ são especialistas. As especialidades citadas pelos professores envolveram as seguintes áreas: 7.8\% são especialistas em Educação Infantil, 3.0\% possuem especialização em Gestão Escolar, assim como em psicopedagogia. Os demais englobam outras áreas do conhecimento como Gestão de Pessoas, Educação Especial e Inclusiva, Metodologia do Ensino, entre outras que não são do campo educacional.

No que tange aos professores com pós-graduação stricto sensu (Mestrado e Doutorado), foram registrados quatro professores mestres, dos quais dois atuam na zona Oeste, um na zona Leste 1 e um na Zona Rural. Dentre os professores em capacitação, dois estavam cursando mestrado, um na zona Leste 2 e outro na Rural, e apenas um cursando doutorado na zona Oeste.

Figura 2 - Nível de formação dos professores da Rede Municipal de Ensino de Manaus nas Zonas Distritais da SEMED

Fonte: Elaborado pelas autoras

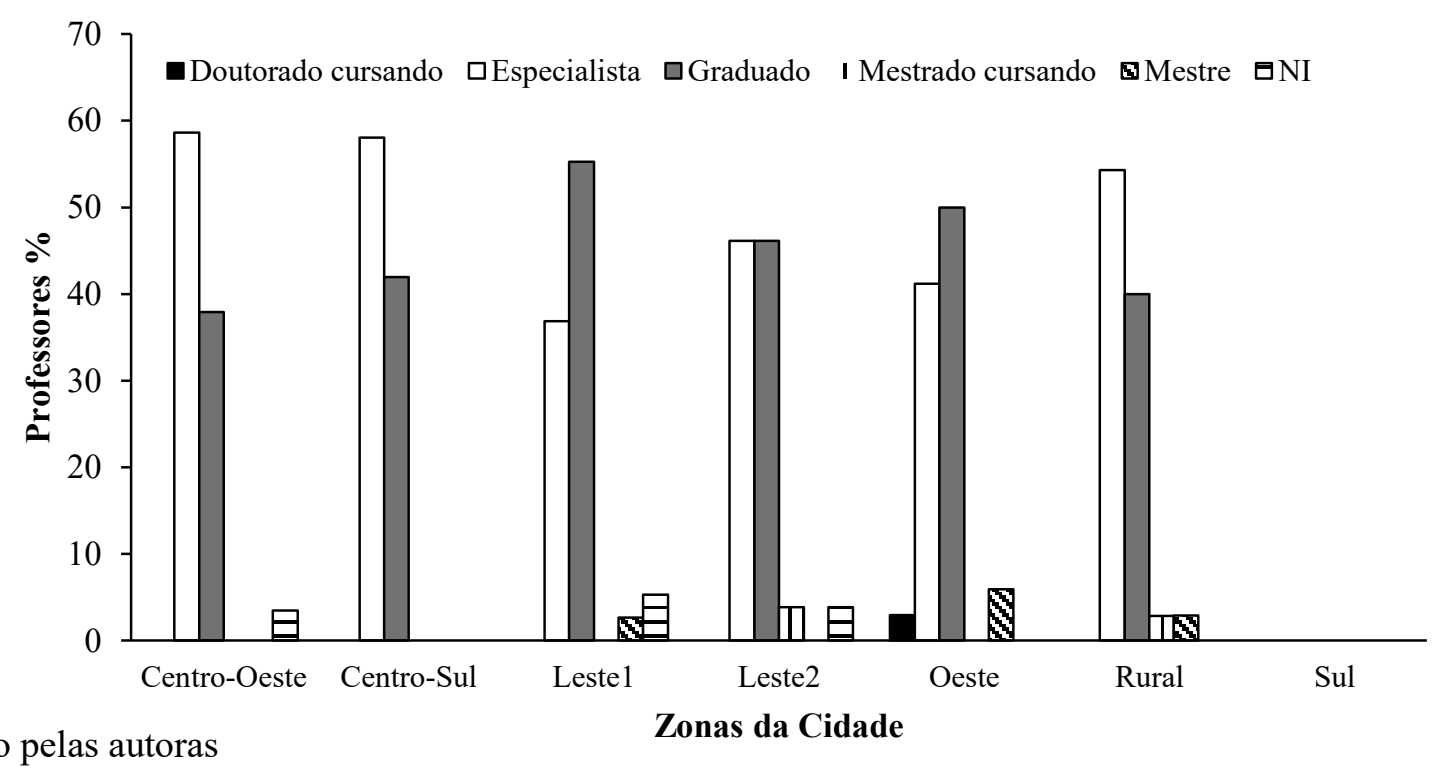

O nível de formação dos professores da Rede Municipal de Ensino de Manaus de acordo com as Zonas Distritais mostra que, em sua maioria, eles têm formação em nível superior e especialização latu sensu na área educacional, no entanto há número reduzido de professores com mestrado e doutorado. Conforme apresentado sobre a formação dos professores participantes da pesquisa, este fato indica que eles tem buscado aperfeiçoar seus conhecimentos na área de atuação. 
De acordo com a Lei de Diretrizes e Bases da Educação Nacional 9394/96 (LBB) (BRASIL, 1996), no capítulo VI, sobre os profissionais da educação, sinaliza a respeito da formação inicial e continuada:

$1^{\circ}$ A União, o Distrito Federal, os Estados e os Municípios, em regime de colaboração, deverão promover a formação inicial, a continuada e a capacitação dos profissionais de magistério.

$\S 2^{\circ}$ A formação continuada e a capacitação dos profissionais de magistério poderão utilizar recursos e tecnologias de educação a distância.

$\S 3^{\circ}$ A formação inicial de profissionais de magistério dará preferência ao ensino presencial, subsidiariamente fazendo uso de recursos e tecnologias de educação a distância.

$\S 4^{\circ}$ A União, o Distrito Federal, os Estados e os Municípios adotarão mecanismos facilitadores de acesso e permanência em cursos de formação de docentes em nível superior para atuar na educação básica pública.

Para Ibernóm (2006), as mudanças acontecem com certa morosidade na educação, onde os aspectos como a falta de condição de trabalho do docente e a desvalorização profissional precisam ser repensadas, de acordo com o autor, trazendo uma nova concepção inerente a profissão, na qual o docente participa de forma ativa, dinâmica e crítica, colaborando para um currículo que trabalhe os aspectos subjetivos, valores e atitudes de forma coletiva, desenvolvendo-o no meio que estão inseridos. A instituição educativa, na visão do referido autor, tem um papel importante de fomentar essas inovações e a profissionalização docente através de um cabedal de ações que permeiam o fazer pedagógico.

Para Nóvoa (1997) a formação do professor possibilita o desenvolvimento profissional, no contexto da autonomia da sua profissão. Com isso os professores buscam e assumem a responsabilidade de sua própria formação e passam a ser sujeitos na implementação de políticas educacionais. Portanto, os aspectos que envolvem o processo de formação do professor perpassam pela efetivação de políticas públicas que contemplem o desenvolvimento de sua formação, bem como a busca pelo conhecimento, a articulação entre teoria e prática, ou seja, fazer a relação entre os saberes de sua prática educativa e aos conhecimentos científicos, colaborando para uma educação de qualidade.

\section{Caracterização do ambiente escolar}

Ao se descrever as características do ambiente escolar que influenciam diretamente na execução das atividades no recinto escolar, os fatores ruído e ineficiência e/ou ausência refrigeração da sala de aula foram os mais citados pelos professores (Tabela 1). 
Tabela 1 - Caracterização do ambiente escolar nas diferentes zonas da cidade de Manaus. $\mathrm{N}=229$.

\begin{tabular}{cccccccccc}
\hline \multirow{2}{*}{$\begin{array}{c}\text { Ambiente } \\
\text { Escolar }\end{array}$} & $\begin{array}{c}\text { Centro- } \\
\text { Oeste }\end{array}$ & $\begin{array}{c}\text { Centro- } \\
\text { Sul }\end{array}$ & $\begin{array}{c}\text { Leste } \\
\mathbf{1}\end{array}$ & Leste 2 & Oeste & Rural & Sul & $\begin{array}{c}\text { Total } \\
\text { Total } \\
\text { \% }\end{array}$ \\
\hline MI & 2 & 4 & 5 & 0 & 2 & 0 & 3 & $\mathbf{1 6}$ & $\mathbf{6 . 9}$ \\
PI & 0 & 0 & 0 & 2 & 0 & 1 & 1 & $\mathbf{4}$ & $\mathbf{1 . 7}$ \\
REF & 9 & 15 & 14 & 14 & 14 & 8 & 8 & $\mathbf{8 2}$ & $\mathbf{3 5 . 8}$ \\
RU & 16 & 11 & 18 & 6 & 18 & 23 & 24 & $\mathbf{1 1 6}$ & $\mathbf{5 0 . 6}$ \\
NI & 2 & 1 & 1 & 4 & 0 & 3 & 0 & $\mathbf{1 1}$ & $\mathbf{4 . 8}$ \\
\hline
\end{tabular}

Legenda: MI: Mobília inadequada; NI: Não informou; PI: Pichação; REF: Refrigeração; RU: Ruído. Fonte: Elaborado pelas autoras

Os resultados mostram que as escolas apresentam precariedade na sua estrutura física, por não disporem de equipamentos que possibilitem o melhor desenvolvimento das aulas como refrigeradores e salas com isolamento acústico, pois a ausência dessas condições estruturais dificulta o desenvolvimento do trabalho dos professores como também interferem na aprendizagem dos alunos.

Isso corrobora com os resultados da pesquisa de Gomes e Brito (2006), a precarização do trabalho docente que envolve a estrutura física das escolas, a demanda de trabalho e o rebaixamento salarial faz parte das dificuldades citadas pelos professores da região sudeste do país.

De acordo Farias (2009) é necessário conceber espaços que propiciem conforto térmico, acústico e iluminação, para se criar condições dignas para os docentes, pois dedicam grande parte de sua vida ao ensino para a promoção de um ambiente saudável.

Segundo Hans (2001), alguns estudos têm demonstrado que o ruído em sala de aula encontra-se acima dos valores recomendados pela Associação Brasileira de Normas Técnicas (ABNT) e Organização Mundial da Saúde (OMS). Esse fato é preocupante pois, esses ruídos contemplam fatores internos como conversas, mobiliário, equipamentos e os fatores externos compõe tráfego, proximidades dos centros urbanos e movimentação de pessoas.

\section{Fatores que levam ao desencadeamento de doenças}

Quanto aos fatores de estresse, de forma geral, as maiores causas apontadas pelos profissionais foram o fator salarial (62.4\%), a ausência de acompanhamento familiar na vida 
escolar dos discentes (19.6\%) e a infraestrutura precária do recinto escolar (10.9\%), conforme a Tabela 2.

Tabela 2 - Fatores de estresse nas escolas do município de Manaus. N=229.

\begin{tabular}{|c|c|c|c|c|c|c|c|c|c|}
\hline \multirow[b]{2}{*}{$\begin{array}{c}\text { Fatores de } \\
\text { estresse }\end{array}$} & \multicolumn{9}{|c|}{ Zonas } \\
\hline & $\begin{array}{l}\text { Centro- } \\
\text { Oeste }\end{array}$ & $\begin{array}{l}\text { Centro- } \\
\text { Sul }\end{array}$ & $\begin{array}{l}\text { Leste } \\
1\end{array}$ & $\begin{array}{l}\text { Leste } \\
2\end{array}$ & $\begin{array}{l}\text { Oest } \\
\text { e }\end{array}$ & $\begin{array}{l}\text { Rura } \\
\text { l }\end{array}$ & $\begin{array}{l}\text { Su } \\
1\end{array}$ & $\begin{array}{l}\text { Tota } \\
\text { l }\end{array}$ & Total \% \\
\hline AFA & 3 & 11 & 3 & 9 & 9 & 6 & 4 & 45 & 19.6 \\
\hline IND & 1 & 0 & 1 & 1 & 0 & 1 & 0 & 4 & 1.8 \\
\hline INF & 3 & 6 & 7 & 0 & 4 & 1 & 4 & 25 & 10.9 \\
\hline SAL & 21 & 12 & 25 & 12 & 21 & 25 & 27 & 143 & 62.4 \\
\hline VIO & 0 & 0 & 0 & 2 & 0 & 1 & 0 & 3 & 1.4 \\
\hline NI & 1 & 2 & 2 & 2 & 0 & 1 & 1 & 9 & 3.9 \\
\hline
\end{tabular}

Legenda: AFA: Ausência familiar; IND: Indiciplina: INF: Infraestrutura; VIO: Violência; SAL: Salário; NI: Não informou.

Fonte: Elaborado pelas autoras

As políticas de valorização profisssional, o Plano Nacional de Educação (PNE) com vigência de 2014 a 2024, traz na Meta 17 "valorizar os (as) profissionais do magistério das redes públicas de educação básica de forma a equiparar seu rendimento médio ao dos (as) demais profissionais com escolaridade equivalente, até o final do sexto ano de vigência deste PNE”.

Com isso, essa meta visa equiparar o salário dos professores, pois os seus rendimentos são inferiores aos de outras profissões, sendo observado esse decréscimo independente do nível de escolaridade, pois a diferença entre o salário médio dos profissionais do magistério com escolaridade de nível médio comparado com o de outros profissionais com igual nível de escolaridade é 9\% superior. Já entre os profissionais do magistério com escolaridade superior ou mais e os demais profissionais com a mesma escolaridade existe uma defasagem de $57 \%$ (BRASIL, 2014, p. 53).

Nas políticas públicas referentes a essa valorização, a Lei $n^{\circ}$ 11.738/2008 (BRASIL, 2008), que aprovou o Piso Salarial Profissional Nacional para os Profissionais do Magistério Público da Educação Básica (PSPN), passou a apresentar um gradativo avanço para essa valorização, ao estabelecer o piso salarial para esses profissionais.

Contudo, os professores nas pesquisas, no que se refere ao item salário, apresentam insatisfação. Na pesquisa realizada por Landini (2006) os fatores que causam desgaste com à profissão docente estão relacionados a uma sobrecarga de trabalho, à falta de apoio dos pais 
dos alunos, a um sentimento de inutilidade em relação ao trabalho que realizam, à concorrência com outros meios de transmissão de informação e cultura e, também, aos baixos salários.

Conforme nos afirma Paschoalino (2007, p. 48), “o descompasso da valorização do trabalho docente no sistema capitalista é um dos aspectos de sofrimento do professor que luta para que seja reconhecido pelo trabalho que realiza [...]". Ademais, segundo a autora, isso afeta diretamente a relação do professor com o aluno, influenciando diretamente no processo de ensino e aprendizagem.

No que se refere ao acompanhamento familiar na vida escolar do educando, Villa (2003) relata que escola e família são um dos principais espaços onde acontece a preparação para a vida em seus diversos aspectos, a priori essa preparação ficava a cargo da família que orientava o aprendizado que ocorria em casa, no século XX esse papel passou a ser dividido com a escola, sendo a escola responsável pelo conteúdo formal e a família responsável pela educação moral, cultural e religiosa da criança.

A parceria entre a escola e a família é importante, pois o envolvimento da família possibilita um melhor rendimento na vida escolar do aluno, a ausência desse envolvimento pode ocasionar a falta de interesse e a desvalorização da educação.

Quanto ao debate sobre o papel dos pais na escolarização dos filhos e suas implicações para a aprendizagem, na escola, há aspectos a serem ressaltados. A família como impulsionadora da produtividade escolar e do aproveitamento acadêmico e o distanciamento da família, podendo provocar o desinteresse escolar e a desvalorização da educação, especialmente nas classes menos favorecidas (POLONIA; DESSEN, 2005, p. 2).

A ausência de acompanhamento familiar na vida escolar do aluno, citado pelos professores pesquisados, também é comum na pesquisa realizada por Oliveira e Andreu (2015). Segundo os referidos autores, a ausência de acompanhamento familiar na vida escolar do aluno está associada às situações sociais e políticas e interferem na saúde do professor como indisciplina, desvalorização e violência.

O desinteresse do aluno pelo ensino e os problemas de indisciplina são, muitas vezes, associados a outro problema citado pelos professores e que merece destaque: a ausência da família na escola. Essa ausência compromete o trabalho docente, pois há uma compreensão entre os professores de que os pais ou responsáveis deveriam contribuir na educação escolar de seus filhos. Na medida em que essa parceria não funciona, é repassada diretamente para a escola toda a tarefa de educar, multiplicando o trabalho do professor (OLIVEIRA; ANDREU, 2015, p. 9). 
Um aspecto relevante, foi enfocado por Ananias (2000) e Nunes Sobrinho (2003), em que a escola precisa contemplar em seu Projeto Político Pedagógico a integração família e escola por meio de ações conjuntas, em que possam exercer seu papel de forma a complementar o desenvolvimento do aluno.

Outro fator relevante, causador de estresse apontado pelos docentes na pesquisa, refere-se às condições de trabalho na infraestrutura das escolas. As condições de trabalho envolvem um conjunto de recursos que se constituem como estrutura física, materiais e meios para a realização das atividades pedagógicas, a ausência dessas condições traz impacto negativo na atuação dos professores e fazer pedagógico (SILVA; GUILLO, 2015).

A precarização dessa estrutura tem influenciado de forma negativa o trabalho do professor. De acordo com Silva e Guillo (2015), a relação entre o processo de trabalho docente e as condições em que ele é realizado merece destaque, por ser esta relação um fator de possível adoecimento tanto físico como mental dos professores.

Segundo Veodato e Monteiro (2008), a questão da indisciplina dos alunos em sala de aula pode ser um dos principais fatores de estresse do professor e causa problemas que interferem no processo de ensino e aprendizagem, pois em um ambiente em que há barulho, movimentação, alunos indisciplinados, salas superlotadas e sem espaço físico, o professor terá dificuldade de exercer um bom trabalho, tendo em vista que o mesmo não se sente, na maioria dos casos, preparado para lidar com esses alunos.

As pesquisas que envolvem a análise do adoecimento do professor no levantamento realizado por Oliveira (2015), apresentam dados de um alto índice de professores e casos de adoecimento através de dados estatísticos e uma grande quantidade de professores com licenças e atestados médicos por questões de doença.

No presente estudo, os maiores percentuais de licença médica foram registrados nas zonas Sul (55.5\%), Rural (45.7\%) e Centro-Oeste (37.9\%). As zonas Sul e Centro-oeste fazem parte do perímetro urbano da cidade, enquanto a zona Rural que compreende a zona rodoviária e ribeirinha e encontra-se distante do centro da cidade, e neste sentido não observou-se diferença quanto as licenças dos professores que atuam na região urbana e rural.

Em relação ao tempo de licença médica, que os docentes estiveram afastados por motivo de doença, variou de 3 (três) dias a dois anos, sendo que 44\% dos professores entrevistados permaneceu de licença por um período maior que 30 dias, $28 \%$ de 7 a 14 dias e $10.7 \%$ de 3 a 6 dias (Tabela 3). 
Tabela 3 - Tempo de licença médica da Rede Municipal de Ensino de Manaus de acordo nas Zonas Distritais. $\mathrm{N}=75$ professores licenciados

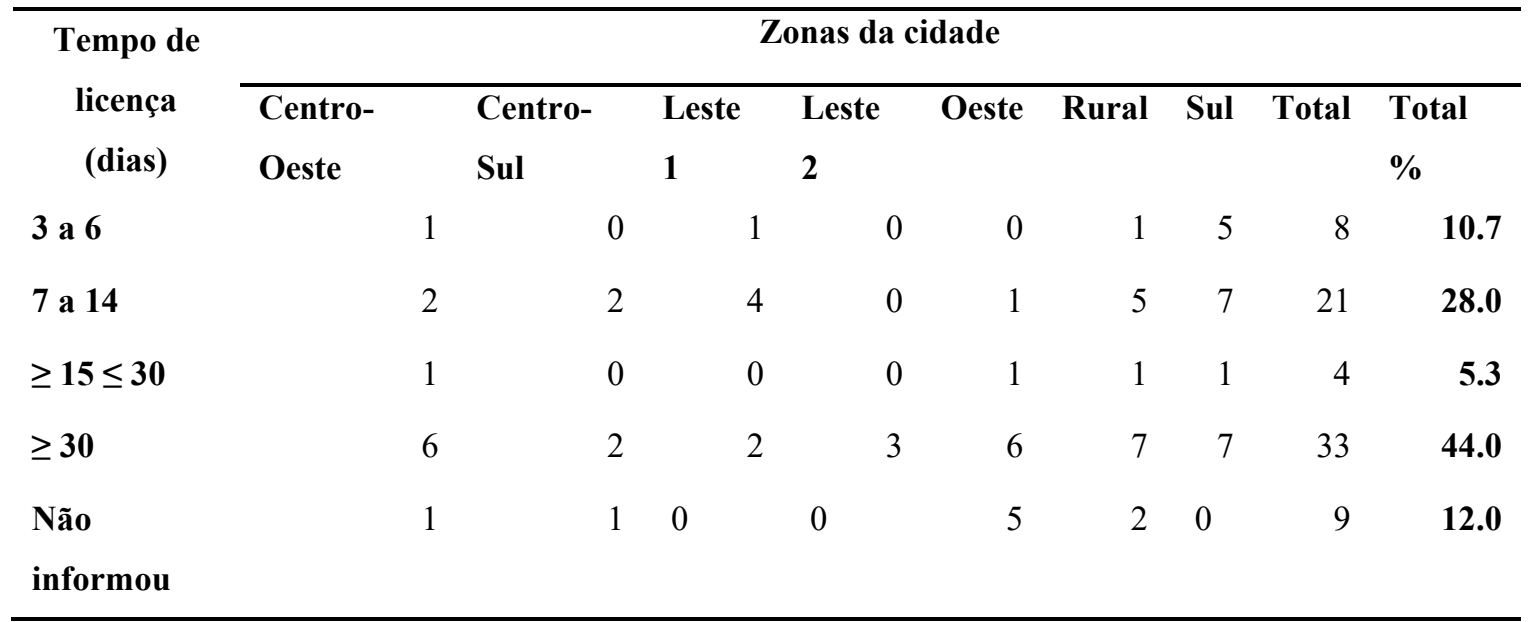

Fonte: Elaborado pelas autoras

As diversas funções que o professor precisa desempenhar na escola, e pelas quais é cobrado, tem influenciado diretamente na sua saúde, prevalecendo o aumento de licenças médicas, o que indica a necessidade de acompanhamento para manutenção da saúde desses professores.

O professor, extenuado no processo de intensificação do trabalho, teria a sua saúde fragilizada e estaria mais susceptível ao adoecimento. Pode-se supor, ainda, que a hipersolicitação em regime de urgência o teria levado a ultrapassar ou a deixar de reconhecer o seu próprio limite, expondo-o aos riscos de adoecimento (ASSUNÇÃO; OLIVEIRA, 2008, p. 363).

Em relação ao percentual de docentes afastados devido quadro de adoecimento em decorrência do trabalho com consequente desencadeamento de distúrbios emocionais, todas as zonas apresentaram o quadro de adoecimento maior que $50 \%$. Destacou-se a zona Sul (94.4\%), seguida da zona Centro-Oeste (86.6 \%) e zona Rural (85.7\%) (Figura 3). 
Figura 3 - Professores da Rede Municipal de Ensino de Manaus que apresentaram quadro de adoecimento de acordo com as Zonas Distritais

Fonte: Elaborado pelas autoras

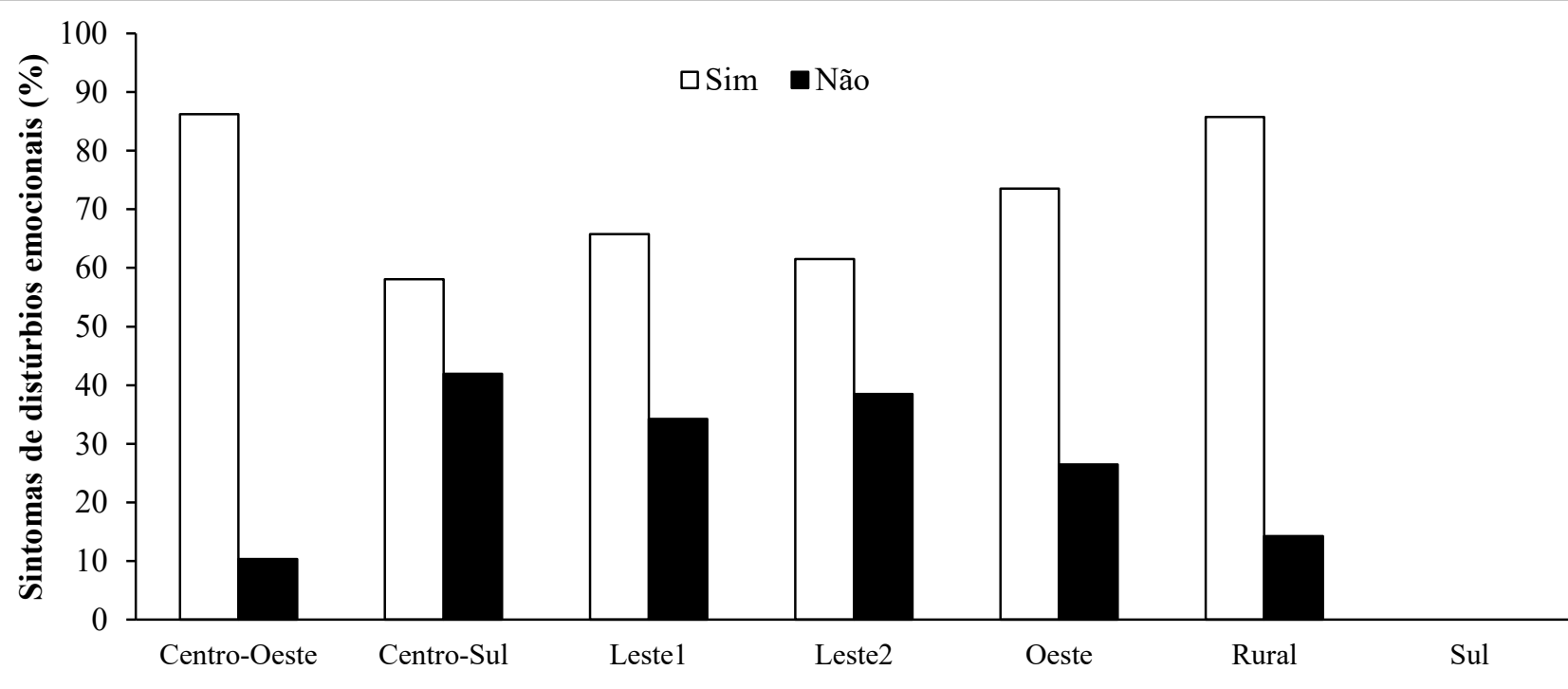

Zonas da cidade

Esse quadro de adoecimento é explicitado Oliveira (2015, p. 74) quando afirma que:

[...] as condições de trabalho cotidianas geram uma expectativa no trabalhador e a ausência dessas condições somada à intensificação do trabalho o professor pode ter seu trabalho impedido, o que também pode gerar riscos de adoecimento.

Os resultados corroboram com a afirmação de Oliveira (2015) e Vasconcelos (2005) que retratam em seu estudo com professores do ensino fundamental que entre as razões de adoecimento e do sofrimento estão as condições de trabalho. Com isso, a ausência de condições de trabalho tem afetado a saúde desses profissionais e consequentemente o afastamento do trabalho por meio de licença médica.

A precarização do trabalho do professor em relação às condições que são disponibilizados, sejam estruturais ou funcionais, tem favorecido o seu adoecimento e influenciam diretamente na qualidade da educação. Assim, há necessidade de se repensar acerca de melhores condições e investimento para o exercício da profissão docente nas escolas pesquisadas.

Os problemas de saúde apresentados pelos professores da referida rede de ensino durante atuação em sala de aula são evidenciados na Tabela 4, dos quais são citados, as doenças psicossomáticas em maior percentual com 24\%, seguido por doenças osteomusculares (18.7\%) e problemas na voz $(11.3 \%)$. 
Tabela 4 - Doenças apresentados pelos professores da Rede Municipal de Ensino de Manaus de acordo com as Zonas Distritais. $\mathrm{N}=229$ professores

\begin{tabular}{|c|c|c|c|c|c|c|c|c|c|}
\hline \multirow[b]{2}{*}{ Doenças } & \multicolumn{9}{|c|}{ Zonas da cidade } \\
\hline & Centro Oeste & Centro Sul & Leste 1 & $\begin{array}{l}\text { Leste } \\
2\end{array}$ & Oeste & Rural & Sul & Total & Total\% \\
\hline Psicossomáticas & 7 & 9 & 5 & 10 & 7 & 6 & 11 & 55 & 24.0 \\
\hline Gástrico & 0 & 0 & 6 & 0 & 4 & 3 & 1 & 14 & 6.1 \\
\hline $\begin{array}{l}\text { Hipertensão } \\
\text { arterial }\end{array}$ & 1 & 1 & 1 & 1 & 1 & 1 & 2 & 8 & 3.5 \\
\hline Osteomuscular & 7 & 4 & 4 & 1 & 4 & 8 & 15 & 43 & 18.8 \\
\hline Voz & 4 & 2 & 5 & 1 & 6 & 4 & 4 & 26 & 11.4 \\
\hline Não informou & 5 & 2 & 3 & 3 & 3 & 6 & 0 & 22 & 9.6 \\
\hline Outros & 1 & 0 & 1 & 0 & 0 & 1 & 1 & 4 & 1.7 \\
\hline $\begin{array}{l}\text { Não } \\
\text { apresentaram } \\
\text { nenhuma } \\
\text { doença }\end{array}$ & 5 & 13 & 13 & 10 & 9 & 7 & 2 & 57 & 24.9 \\
\hline
\end{tabular}

Legenda: Psicossomáticas: ansiedade, depressão, estafa, síndrome do pânico; Gástrico: gastrite; Osteomuscular: dor lombar, hérnia de disco, dores no joelho; Voz: nódulos nas cordas vocais e rouquidão; Outros: ruptura na panturrilha e rinite.

Fonte: Elaborado pelas autoras

As doenças psicossomáticas fazem parte de um conjunto de sintomas que foram apresentados pelos professores pesquisados. Desta forma, eles têm desenvolvido quadro de adoecimento físico e psíquico.

Para Freitas (2007) essas doenças psicossomáticas são frequentes entre professores de todos os níveis e ambientes de trabalho como a gastrite, taquicardia, hipertensão, irritabilidade, insônia, depressão e síndrome do pânico e estão entre os males mais diagnosticados. Conformando os resultados encontrados nessa pesquisa.

As doenças psicossomáticas são manifestadas, principalmente em pessoas que vivem ou trabalham em ambientes tensos, que exigem muito do estado psicossocial do indivíduo, assim as condições de trabalho e situações as quais o professor é exposto favorecem esse adoecimento (SILVA; GUILO, 2015).

O exercício da profissão docente está inserido no contexto em que se incute no professor, além da atividade de mediar o conhecimento, outras situações que a escola passa assumir e ele passa a ser uns dos principais articuladores dessa demanda. Para Oliveira (2006, p. 2012), os professores são, em geral, considerados os principais responsáveis pelo desempenho dos alunos, da escola e do sistema, no contexto atual de reformas educacionais e de uma nova regulação educativa. Diante das variadas funções que a escola pública assume, 
os professores encontram-se frequentemente diante da necessidade de responder às exigências que estão para além de sua formação.

No que se refere a pesquisas que relatam sobre as doenças que os professores são acometidos, Oliveira e Andreu (2015) relatam que as doenças psicossomáticas, perfazem $55 \%$, problemas de voz e doenças musculoesqueléticas (60\% e 30\%, respectivamente). Outro estudo, o de Gasparini, Barreto e Assunção (2005), que envolveu as causas do afastamento de trabalho dos profissionais de ensino em Belo Horizonte, demonstrou que elas estão ligadas aos transtornos psíquicos, com 15\%, as doenças do aparelho respiratório que compreendem $12 \%$, e as doenças do sistema osteomuscular com $11 \%$. O conhecimento a respeito do adoecimento dos professores está presente nas pesquisas dos referidos autores, assim como as doenças que são comuns à maioria dos docentes no exercício da profissão.

No que diz respeito às doenças osteomusculares como dor lombar, hérnia de disco, dores no joelho, elas estão presentes no cotidiano dos professores, pois eles ficam longos períodos explicando conteúdos ou escrevendo no quadro, a ergonomia é inadequada, como mesas e cadeiras, luminosidade, acústica entre outros.

Muitas organizações, incluindo o ambiente escolar, não oferecem condições ergonômicas adequadas, que estejam em conformidade com a legislação trabalhista e, em especial, com o que dispõe a norma regulamentadora 17 (NR 17), a qual preconiza estabelecer parâmetros adaptativos que garantam condições adequadas de trabalho. Diante disto, os sintomas osteomusculares têm sido uma preocupação dos pesquisadores, pois se trata de uma questão de saúde e trabalho, em virtude dos custos e o impacto na qualidade de vida dos trabalhadores (ALVES; ARAÚJO; AGUIAR, 2014, p. 28).

Os professores pesquisados também citaram problemas na voz, sendo a voz um dos principais instrumentos para garantir a comunicação ou informação, assim, "constata-se que os professores são, efetivamente, profissionais com maior risco vocal devido ao desgaste vocal resultante do desempenho profissional, associado na maioria das situações à falta de (in)formação em voz" (GUIMARÃES, 2004, p. 33). Segundo Medeiros, Barreto e Assunção (2006), a disfonia tem se tornado frequente causa de afastamento do trabalho, provocando efeitos negativos na vida do professor, resultando na diminuição da qualidade vocal desse profissional. 


\section{Considerações finais}

As discussões que envolvem a docência são latentes, entre as nuances encontradas, segundo a pesquisa, chama atenção o adoecimento do professor e as condições de trabalho. Neste sentido, foi evidenciado pelos professores que as escolas apresentam precariedade na sua estrutura física, por não dispor de equipamentos que possibilitem o melhor desenvolvimento das aulas, como refrigeradores e salas com isolamento acústico, sendo que as ausências dessas condições estruturais dificultam o desenvolvimento do trabalho dos professores como também podem interferir na aprendizagem dos alunos.

No que diz respeito às doenças apresentadas pelos docentes em decorrência de situações de vulnerabilidade no trabalho, o estudo possibilitou identificá-las, dentre as patologias, as psicossomáticas foram as mais citadas, seguidos de doenças osteomusculares e nas cordas vocais. Com relação a esse quadro de adoecimento citado pelos docentes, há a necessidade de acompanhamento da saúde dos docentes para uma melhor qualidade de vida profissional.

Com relação a fatores que causam estresse nos professores, a ausência familiar na vida escolar do aluno, a indisciplina e o fator salarial foram os mais citados, desta forma é fundamental fomentar parceria entre a escola e a família, pois o envolvimento da família possibilita um melhor rendimento na vida escolar do aluno, e a ausência desse envolvimento pode ocasionar a falta de interesse e desvalorização da educação.

Quanto à indisciplina, há necessidade de se trabalhar essa questão com a participação da família, não sendo a indisciplina concebida de forma isolada, tendo em visto que ela está ligada a fatores econômicos, políticos e sociais.

Portanto, em meio as evidências encontradas na pesquisa há a necessidade de se possibilitar aos docentes condições estruturais adequadas no ambiente escolar, para o exercício da profissão, bem como investimentos na valorização profissional e fomentar ações ou parcerias com instituições públicas ou privadas, entre os profissionais da saúde e a escola para acompanhamento da saúde e suporte aos docentes. 


\section{REFERÊNCIAS}

ALVES, C. S.; ARAÚJO, M. M.; AGUIAR, C. A. postura ergonômica do profissional docente: um estudo de caso do centro de atenção integrada à criança e ao adolescente (CAIC) Senador Carlos Jereissati, em Russas-CE. Tecnologia \& Informação, v. 1, n. 3, p. 20-32, 2014.

ANANIAS, M. Propostas de educação popular em Campinas: “as aulas noturnas”. Cadernos do CEDES, n. 51, p. 66-77, 2000.

BRASIL. Lei n. 11.738, de 16 de julho 2008. Regulamenta a alínea "e" do inciso III do caput do art. 60 do Ato das Disposições Constitucionais Transitórias, para instituir o piso salarial profissional nacional para os profissionais do magistério público da educação básica. Diário Oficial da União: Seção 1, Brasília, DF, p. 1, 17 jul. 2008. PL 7431/2006

CARLOTTO, M. S. A síndrome de burnout e o trabalho docente. Psicologia em estudo, v. 7, n. 1, p. 21-29, 2002.

CARLOTTO, M. S.; PALAZZO, L. S. Síndrome de burnout e fatores associados: um estudo epidemiológico com professores. Caderno Saúde Pública, v. 22, p. 1017-1026, 2006.

CODO, W.; VASQUES-MENEZES, I. O que é burnout? Educação: carinho e trabalho. In: CODO, W. (Org.) Educação: carinho e trabalho. Rio de Janeiro: Vozes, 1999. p. 237-255.

COSTA, F. R. C. P.; ROCHA, R. Fatores estressores no contexto de trabalho docente.

Revista Ciências Humanas, v. 6, n.1, p. 18-43, 2013.

CRUZ, R. M. et al. Saúde docente, condições e carga de trabalho. Revista Electrónica de Investigación y Docência (REID), n. 4, 2010. Disponível em:

http://www.revistareid.net/revista/n4/REID4art8.pdf. Acesso em: 8 out. 2015.

ESTEVE, J. M. O mal-estar docente: a sala de aula e a saúde dos professores. Bauru, SP: EDUSC, 1999.

FARIAS, P. M. Condições do ambiente de trabalho do professor: avaliação em uma escola municipal. 2009. 225 f. Dissertação (Mestrado em Saúde, Ambiente e Trabalho) Universidade Federal da Bahia, Salvador, 2009.

FERREIRA, L. Relações entre trabalho e a saúde de professores na educação básica no Brasil. Fundacentro, São Paulo, abr. 2010. Disponível em: https://fasul.edu.br/portal/files/biblioteca_virtual/7/relaciestrabalho.pdf. Acesso em: 8 out. 2015.

FREITAS, M. E. A carne e os ossos do ofício acadêmico. Organizações \& Sociedade, v. 14, n. $42,2007$.

FREITAS, C. R.; CRUZ, R. M. Saúde e trabalho docente. In: ENCONTRO NACIONAL DE ENGENHARIA DE PRODUÇÃO, 28., 2008, Rio de Janeiro. Anais [...] Rio de Janeiro, 2008. p. 1-15. 
GASPARINI, S. M.; BARRETO, S. M.; ASSUNÇÃO, A. A. O professor, as condições de trabalho e os efeitos sobre sua saúde. Educação e Pesquisa, São Paulo, v. 31, n. 2, p. 189$199,2005$.

GOMES, L.; BRITO, J. Desafios e posibilidades ao trabalho docente e a sua relação com a saúde. Revista Estudos e Pesquisas em Psicologia, Rio de Janeiro, v. 6, n.1, p. 1-14, 2006.

GUIMARÃES, I. Os problemas de voz nos professores: prevalência, causas, efeitos e formas de prevenção. Revista Portuguesa de saúde pública, v. 22, n. 2, 2004.

HANS, R. F. Avaliação de ruído em escolas. Rio Grande do Sul: UFRSPROMEC, 2001.

\section{HERNANDEZ SAMPIERI, R. H. COLLADO, C. F.; LUCIO, P. B. Metodologia de}

Pesquisa. Porto Alegre: Penso, 2013.

IMBERNÓN, F. Formação docente e profissional: formar-se para a mudança e a incerteza. 6. ed. São Paulo: Cortez, 2006.

LANDINI, S. R. Professor, trabalho e saúde: as políticas educacionais, a materialidade histórica e as consequencias para a saúde do trabalhador professor. In: SEMINÁRIO DA REDESTRADO - REGULAÇÃO EDUCACIONAL E TRABALHO DOCENTE, 6., 2006. Rio de Janeiro. Anais [...]. Rio de Janeiro, RJ: UERJ, 2006. p. 1-15.

MACHADO, J. L. A. O professor brasileiro do ensino fundamental público e seu perfil. 2015. Disponível em: https://acervo.plannetaeducacao.com.br/portal/artigo.asp?artigo=2568. Acesso em 20 de ago. 2017.

MEDEIROS, A. M.; BARRETO, S.; ASSUNÇÃO, A. Á. Professores afastados da docência por disfonia: o caso de Belo Horizonte. Caderno saúde coletiva, Rio de Janeiro, v. 14, n. 4, p. 615-624, 2006.

NÓVOA. A. (Org). Os professores e a sua formação. 3 ed. Lisboa: Publicações Dom Quixote; Instituto de Inovação Educacional, 1997.

NUNES SOBRINHO, F. P. O stress do professor do ensino fundamental: o enfoque da ergonomia. In: LIPP, M. N (Org.). O stress do professor. Campinas, SP: Papirus, 2003.

OLIVEIRA, E. da S. G. O "mal-estar" docente como fenômeno da modernidade: os professores no país das maravilhas. Ciências \& Cognição, v. 7, p. 24-41, 2006.

OLIVEIRA, M. F. Trabalho e saúde do professor nas pesquisas em educação. Orientador: Wanderson Ferreira Alves. 2015. 106 f. Dissertação (Mestrado em Educação) - Universidade Federal de Góias, Goiânia, 2015.

OLIVEIRA, R. A. S.; ANDREU, L. G. Condições de trabalho e estresse: um estudo com professores do sexo masculino da educação básica. Trabalho \& Educação, v. 24, n. 3, p. 153-166, 2015. 
PASCHOALINO, J. B. Q. Matizes do mal-estar dos professores do Ensino Médio. 2007. 220 f. Dissertação (Mestrado em Educação) - Universidade Federal de Minas Gerais, Belo Horizonte, 2007.

PENTEADO, R. Z. Relações entre saúde e trabalho docente: percepções de professores sobre saúde vocal. Rev. soc. bras. Fonoaudiol., São Paulo, v. 12, n. 1, p. 18-22, 2007.

PEREIRA, E. F.; TEIXEIRA, C. S.; LOPES, A. D. S. Qualidade de vida de professores de educação básica do município de Florianópolis, SC, Brasil. Ciência Saúde Coletiva, Rio de Janeiro, v. 18, n. 7, p. 1963-70, 2013.

POLONIA, A. C.; DESSEN, M. A. Em busca de uma compreensão das relações entre família escola. Psicol. esc. educ., Campinas, v. 9, n. 2, p. 303-312, 2005.

RABELO, A. O.; MARTINS, A. M. A mulher no magistério brasileiro: um histórico sobre a feminização do magistério. In: CONGRESSO LUSO BRASILEIRO DE HISTÓRIA DA EDUCAÇÃO, 6., 2006, Minas Gerais. Anais [...]. Minas Gerais: UFU, 2006. p. 6167-6176.

SILVA, R. A. O.; GUILLO, L. A. Trabalho docente e saúde: um estudo com professores da educação básica do sudoeste goiano. Itinerarius Reflectionis, Goiânia, v. 11, n. 2, 2015.

VASCONCELOS, A. C. L. A situação de trabalho e saúde mental de professoras da primeira fase do Ensino Fundamental em escolas públicas do município de João Pessoa. 2005. $231 \mathrm{f}$. Dissertação (Mestrado) - Universidade Federal da Paraíba, João Pessoa, 2005.

VEDOVATO, T. G.; MONTEIRO, M. I. Perfil sociodemográfico e condições de saúde e trabalho dos professores de nove escolas estaduais paulistas, Revista Escola Enfermagem USP, São Paulo, v. 42, n. 2, 2008.

VILA, I. Familia y escuela: dos contextos y un solo niño. In: ALFONSO, C. et al. La participación de los padres y madres en la escuela. Barcelona: Editorial GRÀO, 2003. p. 27-38.

\section{Como referenciar este artigo}

ARAÚJO QUEIROZ, J. G. B.; SILVA MARINHO, T. A. Profissão docente e saúde de professores da rede municipal de ensino da cidade de Manaus. Temas em Educ. e Saúde, Araraquara, v. 16, n. 2, p. 575-593, jul./dez. 2020. e-ISSN 2526-3471. ISSN 1517-7947. DOI: https://doi.org/10.26673/tes.v16i2.13807

Submetido em: 16/02/2020

Revisões requeridas: $16 / 06 / 2020$

Aprovado em: 30/07/2020

Publicado em: 27/08/2020 